\title{
How am I able to protect myself from Counterfeit Drugs
}

\author{
Singh N, Dhyani A., Nainwal P., Lall S., Vijay Kumar
}

\begin{abstract}
The market of pharmaceuticals is increasing day by day due to continuous increase in population as well asnumber of diseases. Medicines available freely in the market without prescription are creating serious problems for the health of people. Substandard medicines have raised a major problem globally due to lack of prompt regulatory intervention both in developed and developing countries. These medicines have an easier access to the distribution system. Regular consumption of counterfeit drugs can lead to adverse effect to patients and even death. Public awareness is necessaryto avoid the use of spurious drugs. The present study provides brief overview of counterfeit medicine and their effect on public health.
\end{abstract}

\section{Key words: Counterfeit, Spurious, Trade, Health, Awareness}

\section{INTRODUCTION}

According to the World Health Organization, counterfeit or spurious drugs are those where the identity and source of the manufacturer are intentionally and duplicitously mislabeled. These false drugs are represented with an incorrect ingredient or correct ingredient with wrong proportion or without principle ingredient with fake packing. ${ }^{1}$ Spurious drug possesses an additive danger to the patient. ${ }^{2}$ The emergence of spurious drugs is most frequent in countries with a poor economic situation where various types of infectious diseases are very prominent. But in developed nations where the drugs are used for the treatment of chronic diseases like anticancer, anti allergic, lipid lowering drug are also being counterfeit. ${ }^{3}$ Globally $10 \%$ of the drugs are spurious in nature but in few countries, more than $50 \%$ of supplied drugs are spurious which make the condition even more inferior and it is still increasing with time. ${ }^{4}$ The markets of counterfeit drugs are estimated to be about US \$ 200 billion which represents more than $15 \%$ of the global pharmaceuticals. The market share of counterfeit drug in developed countries is $1 \%$ of total drugs while in developing countries this number reaches $30 \% .^{\mathbf{5 - 6}}$

Eighty-nineadults and thirty infants died in Haiti, India in the year of 1998, on consumption of paracetamol cough syrup which was manufactured by using diethylene glycol, toxic chemical used in antifreeze. ${ }^{7}$

Revised Manuscript Received on November 25, 2019.

*Corresponding Author

Singh N*, School of Pharmacy, Graphic Era Hill University, Dehradun, India.

Dhyani A., School of Pharmacy, Graphic Era Hill University, Dehradun, India.

Nainwal P., School of Pharmacy, Graphic Era Hill University,

Dehradun, India. India.

Vijay Kumar, Department of Physics, Graphic Era Hill University, Dehradun, India.
Lall S., School of Pharmacy, Graphic Era Hill University, Dehradun,

Four persons were died in Maharashtra in the year of 2007due to adverse effect after consumption of spurious drugs. ${ }^{8}$ Three hundred infants died in Kashmir due to ceftriaxone substandard quality of the product in 2012. ${ }^{9}$ Regular consumption of spurious drugs may lead to failure of treatment or even death. ${ }^{10}$ Globally, 0.70 million of deaths were reported due to use of fake drug of tuberculosis and malaria. ${ }^{11}$ Approximately 4.5 million capsules of amoxicillin, ampicillin was seized in Myanmar,2003. ${ }^{12}$ Lipitor drug used in UK for lowering the cholesterol level was detected within the legal supply that lacked sufficient active ingredient. Reportedly in the year 2017, Zypexa used to treat bipolar disorder also lackedsufficient active ingredient which lead to the recall of Zyprex batches. ${ }^{13}$ In America 2007, it was reported that Xenicalused for the treatment of obesitycontained no active ingredients and it had been sold through web siteoperated from outside the USA. Later in 2009 federal agencies found contaminated, counterfeit, and sub potent influenza products.

Food and Drug Administration and Border Protection agency obstruct the product claimed to be generic versions of the influenza medicine, Tamiflu which actually contained vitamin $\mathrm{C}$ along with other substances, it was not effective in treatment of influenza. ${ }^{\mathbf{1 4}}$ According to the research conducted in China in the year 2009 an anti-diabetic traditional medicine which was used to lower the blood glucose level contained 06 times higher than the normal dose of glibenclamidewhich led to 02 deaths and several peoplebeing hospitalized. ${ }^{2} \mathrm{~A}$ case of counterfeit versions of Avastin, cancer-fighting medication manufactured by Roche was notified in February 2012.Bevacizumab that contained salt and starch, but not the active component of the drug. ${ }^{15}$ In 2008, blood thinner heparin was substituted with a cheaper substance that caused patients to have adverse reactions, resulted a nationwide recall of heparin. Medication whose active ingredient came from China, were suspected to be the cause of as many as eighty-onedeaths. A US based company that sold heparin was subjected to 740 lawsuits and eventually they sold the division that produced the drug. ${ }^{\mathbf{1 6}}$

\section{EFFECTS OF COUNTERFEITING}

If the drug isnot effective, patient usually thinks that either diagnosis or prescription is wrong or hemay consult another physician or finishes up having diagnostic tests, resulting an increased medical expenses, mental suffering and absence from work or studies. ${ }^{17-18}$ Consumption of spurious drugs can make patients in a high risk of toxicity that would become calamitous and absolutely clinical disastrous and mortality rates will also be increased. Ingestion of spurious drugs can results in impairment of the liver, 


\section{How am I able to protect myself from Counterfeit Drugs}

kidneys, heart and the central nervous system. The liver is in charge of the metabolism of drugs while the kidneys eliminate them from the body. Due to drug counterfeiting, economic loss is enormous. Many pharmaceutical companies undergo huge economic loss due to selling of fake drugs which are marketed at inexpensive rates. Selling of counterfeit drugs may spoil the market for those companies who have invested a lot in quality, research and development of genuine drugs. ${ }^{\mathbf{1 9 - 2 0}}$

\section{COUNTERFEIT MEDICINES TRADE IN INDIA}

It was reported by United States Trade Representative (USTR) that about twenty per cent of pharmaceutical goods sold in the Indian market are defraud. India was ranked among the top producers that export these medicines to Africa, Canada, Caribbean, South America and the United States. In past year, India took steps to deal with property (IP) challenges and promote IP protection and enforcement. ${ }^{21}$ It was reported by ASSOCHAM in2017 that the fake drugs constitute about US $\$ 4.25$ billion of the total US\$ $14-17$ billion of domestic drug market. ${ }^{22}$ It was estimated that, if the fake drugs market grows at the current rate it will cross US $\$ 10$ billion mark by 2017.Washington Post, 2010 reported that an estimated $12 \%$ to $25 \%$ of all the drugs sold within India are thought to be counterfeit. ${ }^{23}$ Spurious drug worth nearly Rs 4000 crores, which is $20 \%$ of total domestic pharmaceutical business, is manufactured in India. ${ }^{18}$

\section{PROTECTION FROM FAKE MEDICINES}

$>$ Buy the prescribed medicine from well-established chemist shop, make sure to check whether batch number of the medicines are clearly written on the bills.

$>$ Avoid buying the packing that looks odd and anymedicine which is other than prescribed. Do not purchase loose medicine and also note that if the price is lower than the one at which you purchase normally.

$>$ Do not purchase, if there is any grammatical error in the spelling of medicine or thename is different or label looks old or expiry date is not clearly visible.

$>$ Avoid consulting those doctors who themselves dispense loose medicines and do not believe in writing the prescription.

$>$ Destroy the label and therefore the container of the drugs after use. Informthe doctor immediately if there is any adverse reaction like nausea, headache, giddiness, chest pain, etc. If the doctor says that these reactions are not normal then either the patient is allergic to the medicine or it is spurious drug. ${ }^{17}$

\section{HOW TO REDUCE DRUG COUNTERFEITING}

$>$ Public awareness program should be organized regularly, special attention to online pharmacies.

$>$ Management of supply chain and controls of secondary drug markets to be improved.
$>$ Fine and jail sentences for convicted to be strictly implemented.

$>$ Alsopenalize all those who knowingly provide counterfeit medicine to their patients.

$>$ There is a need to cooperate with foreign agencies dealing with counterfeit to avoid drug shortage.

$>$ Promote the use of modern technology to track and trace counterfeiting drugs.

$>$ Drug must be supplied to licensed manufacturers only. $^{20}$

\section{CONCLUSION}

Implementation of stringent law alone cannot solve the problems of counterfeit medicines unless the consumers are not aware about these medicines. The use of more advanced technology for inspection and regulation of pharmaceutical supply may be helpful to overcome the problems of spurious drugs. It is also the moral responsibility of the pharmaceutical companies to come up with the latest technology to reduce free availability of counterfeit drugs in market.

\section{REFERENCES}

1. Available at: http://www.who.int/medicines/publications.

2. Sagar BPS, Zafar R, Singh A., Health Administrator, 2006, 19(1): 6573.

3. Newton PN, Green MD, Fernandez FM, Day NP.,Lancet, 2006, 6(9):602-613.

4. Gupta P, Singhal K, Pandey A.,Int. J Pharm. Sci Res., 2012, 3(11):4057-4064.

5. Ambroise Thomas $\mathrm{P}$, The tragedy caused by fake antimalarial drugs Mediterranean Journal of Haematology and Infectious Diseases,2012, 4(1). PMID: 22708042

6. Verma S, Kumar R, Philip P J.,The Business of Counterfeit Drug in India, A Critical Evaluation, 2014, 4(2): 141-148.

7. Clark C, Pharm J. 2003, 271:453.

8. Khan A, Khar R. Indian J Pharm Sci., 2015; 77 (1):2-7.

9. Available at http://www.thehealthsite.com/news/Kashmir-fake-drugscam-were-spurious-drug-responsible for high infantdeath.

10. Available http://www.policynetwork.net/sites/default/files/IPNCounterfeit.

11. Available at http://www.modernghana.com/news.

12. Kumar R, Int. J. Pharm. Tech. Res., 2014, 6(2):720.

13. Available http://www.mhra.gov.uk/Publication/Safetywarnings/Drug alerts

14. Available at http://www.app1.fda.gov/for consumers/Protect yourself/HealthFraud.htm

15. Available at http:// www.fiercepharma.com/story/feds-nail-keyplayer-counterfeit-avastin-probe.

16. Available at http://www.cnbc.com/id/44759526.

17. Jain SK, Health Administrator, 2006, 19(1):29-40.

18. Available at http://www.hinduonnet.com/thehindu/seta

19. Buowari O,Afrimedic J., 2012, 3(2):1-4.

20. BlackstoneEA,Joseph P, PociaskS, The Health and Economic Effects of Counterfeit Drugs,2014, 7(4): 216-224.

21. Chandna H,Representational image-ThePrint.in, 27 April, 2019, 3:39 pm IST.

22. "Fake drugs constitute $25 \%$ of domestic medicines market in India: ASSOCHAM", Retrieved June 5, 2017.

23. Ramalakshmi in New Delhi, Washington Post 11 Sep 2010. Available from: https://www.pressreader.com/usa/the-washingtonpost/20100911/28840705498. 